\title{
Hibernoma Development in Transgenic Mice Identifies Brown Adipose Tissue as a Novel Target of Aldosterone Action
}

\author{
Maria-Christina Zennaro, Damien Le Menuet, Say Viengchareun, Francine Walker, ${ }^{\star}$ Daniel Ricquier, ${ }^{\ddagger}$ and Marc Lombès \\ INSERM U 246, Institut Fédératif de Recherche Cellules Epithéliales, Faculté de Médecine Xavier Bichat, and *Service \\ d'Anatomo-pathologie, Hôpital Bichat, 75018 Paris, France; and ${ }^{\ddagger}$ CEREMOD, Centre de Recherche sur l'Endocrinologie Moléculaire \\ et le Développement, CNRS, 92190 Meudon, France
}

\begin{abstract}
Aldosterone is a major regulator of salt balance and blood pressure, exerting its effects via the mineralocorticoid receptor (MR). To analyze the regulatory mechanisms controlling tissue-specific expression of the human MR (hMR) in vivo, we have developed transgenic mouse models expressing the SV40 large T antigen (TAg) under the control of each of the two promoters of the hMR gene (P1 or P2). Unexpectedly, all five P1-TAg founder animals died prematurely from voluminous malignant liposarcomas originating from brown adipose tissue, as evidenced by the expression of the mitochondrial uncoupling protein ucp1, indicating that the proximal P1 promoter was transcriptionally active in brown adipocytes. No such hibernoma occurred in P2-TAg transgenic mice. Appropriate tissue-specific usage of P1 promoter sequences was confirmed by demonstrating the presence of endogenous MR in both neoplastic and normal brown adipose tissue. Several cell lines were derived from hibernomas; among them, the T37i cells can undergo terminal differentiation into brown adipocytes, which remain capable of expressing ucp1 upon adrenergic or retinoic acid stimulation. These cells possess endogenous functional MR, thus providing a new model to explore molecular mechanisms of mineralocorticoid action. Our data broaden the known functions of aldosterone and suggest a potential role for MR in adipocyte differentiation and regulation of thermogenesis. (J. Clin. Invest. 1998. 101:1254-1260.) Key words: mineralocorticoid receptor $\bullet$ alternative promoters $\bullet$ thermogenesis • ucp $1 \cdot$ steroid receptors
\end{abstract}

\section{Introduction}

Expression of the mineralocorticoid receptor $(\mathrm{MR})^{1}$ is restricted to specific tissues, including sodium reabsorbing epithelia (1), some areas of the brain $(2,3)$, and the cardiovascular system (4-6). Although physiological effects of aldosterone on sodium and potassium homeostasis are well established, the

Address correspondence to Marc Lombès, INSERM U 246, Institut Fédératif de Recherche Cellules Epithéliales, Faculté de Médecine Xavier Bichat, 16, rue Henri Huchard, BP416, 75870 Paris Cedex 18, France. Phone: 33-1-44-85-63-19; FAX: 33-1-42-29-16-44; E-mail: mlombes@bichat.inserm.fr

Received for publication 2 October 1997 and accepted in revised form 20 January 1998

J. Clin. Invest.

(C) The American Society for Clinical Investigation, Inc. 0021-9738/98/03/1254/07 \$2.00

Volume 101, Number 6, March 1998, 1254-1260

http://www.jci.org mechanism of MR action in both epithelial and nonepithelial target tissues is still poorly understood. In particular, the molecular mechanisms underlying mineralocorticoid signaling and the spectrum of primary mineralocorticoid-regulated target genes remain unclear.

Both in humans and rodents, multiple MR mRNA isoforms arising from alternative promoter utilization have been identified $(7,8)$. Two human MR (hMR) transcripts, hMR $\alpha$ and $\mathrm{hMR} \beta$, are expressed at approximately the same level in kidney, colon, heart, epidermis, and sweat glands; however, their relative abundance varies among these tissues, and there is strong evidence for existence of other hMR mRNA variants, most notably in the heart (9). Recently, we have shown that hMR gene transcription is under the control of two promoter regions, $\mathrm{P} 1$ and $\mathrm{P} 2$, located upstream of the two first untranslated exons $1 \alpha$ and $1 \beta$, respectively. Transient transfection studies have demonstrated that these promoters differ both by their basal as well as their corticosteroid-regulated transcriptional activity, in that only the distal P2 promoter is activated by aldosterone, whereas both regions are responsive to glucocorticoids (10).

In an attempt to study the regulatory mechanisms controlling MR expression in vivo, and to establish cellular models suitable for precise analysis of mineralocorticoid signaling both at the cellular and molecular level, we have developed a targeted oncogenesis strategy using different regulatory regions of the hMR gene fused to the large tumor antigen (TAg) of simian virus 40 (SV40) to direct oncogene expression in normally MR-expressing cells. Unexpectedly, all transgenic founder mice carrying $1.2 \mathrm{~kb}$ of the proximal $\mathrm{P} 1$ promoter region linked to TAg precociously developed voluminous malignant liposarcomas originating from brown adipose tissue (BAT). From these tumors we derived several cell lines harboring both immortalized features and differentiated characteristics of brown adipocytes. In both tumors and cell lines, as well as in normal BAT, we were able to detect endogenous MR. We have thus identified a novel aldosterone target tissue and established cellular models suitable for further studies on MR function as well as identification and characterization of aldosterone-induced genes.

\section{Methods}

Generation of P1-TAg constructs and transgenesis. The P1-TAg transgene was constructed using the transgenesis vector H31 kindly provided by Dr. L.M. Houdebine (INRA, Jouy en Josas, France) (Fig.

1. Abbreviations used in this paper: BAT, brown adipose tissue; GAPDH, glyceraldehyde-3-phosphate dehydrogenase; GR, glucocorticoid receptor; hMR, human MR; MR, mineralocorticoid receptor; mMR, mouse MR; SV40 TAg, simian virus 40 large tumor antigen; ucp1, uncoupling protein 1. 


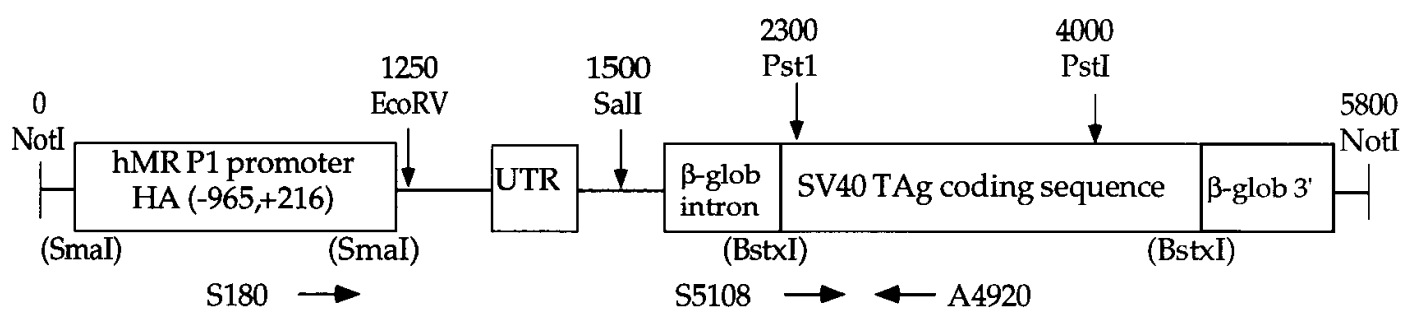

Figure 1. Schematic representation of the P1-TAg transgene. 1.2 $\mathrm{kb}$ of the proximal hMR promoter region was inserted upstream of the SV40 TAg coding sequence into the optimized vector $\mathrm{H} 31$, which contains stabiliz-

ing sequences for mRNA (UTR, untranslated region) and the terminal block of the human $\beta$-globin, including the last intron and the polyadenylation site. Restriction sites used for cloning are indicated in parentheses. Oligonucleotides S180, S5108, and A4920 used for PCR amplification are positioned on the transgene.

1). A HindIII-AvaII fragment $(-965,+216)$ containing the $h M R$ proximal promoter region (P1) and the beginning of the first untranslated exon $1 \alpha$ was blunt-ended using Klenow DNA polymerase (GIBCO BRL, Gaithersburg, MD) and ligated into the SmaI site of the H31 plasmid. The SV40 TAg coding region (2.3-kb StuI-BamHI fragment) was inserted into the BstXI site of the P1-H31 plasmid after fill-in of recessive ends with Klenow enzyme. The transgene was separated from plasmid vector sequences by NotI digestion and purified after agarose gel electrophoresis with Elutip-d columns (Schleicher \& Schuell, Dassel, Germany) and ethanol precipitation. Microinjections into fertilized oocytes derived from B6D2 mice were realized at the Service d'Expérimentation Animale et Transgenèse (SEAT, CNRS, Villejuif, France).

Founders were identified by PCR analyses of tail DNAs from 2-wk-old mice using oligonucleotides specific to the SV40 TAg (sense primer S5108: 5'-TTGAAAGGAGTGCCTGGGGGAAT-3'; antisense primer A4920: 5'-CAGTTGCATCCCAGAAGCCTCCA) and to the P1 region (sense primer S180: 5'-TGCAACAGGTAGGCGAGAGA-3'); PCR conditions are available upon request. Number of integrated copies of transgenes was determined by Southern blot analysis.

Histology. Organs were fixed in 4\% paraformaldehyde in PBS, dehydrated, and paraplast-embedded. $7-\mu \mathrm{m}$ sections were cut and stained with hematoxylin and eosin.

Ribonuclease protection assays and Northern blot analyses. Total RNA was isolated from mouse tissues with Trizol (GIBCO BRL) according to the manufacturer's recommendations. For ribonuclease protection assays, Bluescript-KS plasmids (Stratagene, La Jolla, CA) containing a PstI fragment of exon 2 of the mouse MR (mMR, kindly provided by Drs. S. Berger and G. Schütz, Heidelberg, Germany) or a BamHI-StuI fragment of SV40 TAg were linearized by StuI and HinfI, respectively, and labeled antisense riboprobes synthesized with T3 and T7 RNA polymerases. The rat glyceraldehyde-3-phosphate dehydrogenase (GAPDH) probe was synthesized with T7 RNA polymerase, after digestion of a Bluescript-SK-GAPDH plasmid by PvuII-StyI. RNase protection assays were performed as described previously (11). Briefly, $50 \mu \mathrm{g}$ of total RNA was hybridized overnight at $55^{\circ} \mathrm{C}$ with $4 \times 10^{5} \mathrm{cpm}$ probe. Digestion with RNase A and $\mathrm{T}$ was performed at $30^{\circ} \mathrm{C}$ for $1 \mathrm{~h}$ followed by digestion by proteinase $\mathrm{K}$ at $37^{\circ} \mathrm{C}$ for $30 \mathrm{~min}$. After phenol extraction and ethanol precipitation, protected fragments were electrophoresed on $6 \%$ polyacrylamide/urea gel. Unprotected mMR, TAg, and GAPDH riboprobes migrated at 452,365 , and $184 \mathrm{bp}$, with protected fragments migrating at 380,291 , and $164 \mathrm{bp}$, respectively.

Northern blot analysis was performed by standard techniques (12), using an $\left[\alpha{ }^{-32} \mathrm{P}\right]$-labeled PCR fragment encompassing the coding region of the rat uncoupling protein 1 (ucp1) gene as probe (Megaprime DNA labeling system; Amersham, Arlington Heights, IL).

Tissue culture. Cell lines were derived from 2-wk-old transgenic mice (founders 34 and 37, Table I). Interscapular tumors were removed under sterile conditions, cut in small pieces, rinsed twice with defined medium (DME-Ham's F12 [GIBCO BRL] supplemented with $10 \%$ FCS, $2 \mathrm{mM}$ glutamine, $100 \mathrm{IU} / \mathrm{ml}$ penicillin, $100 \mu \mathrm{g} / \mathrm{ml}$ streptomycin, $20 \mathrm{mM}$ Hepes) and teased with two forceps in a Petri dish containing $10 \mathrm{ml}$ of defined medium. After centrifugation, pelleted cells were rinsed twice and grown at $37^{\circ} \mathrm{C}$ in a humidified atmosphere with $5 \% \mathrm{CO}_{2}$. Three cell lines were established, T34, T37s, and T37i, and the latter was further analyzed. Differentiation into adipocytes was achieved by treatment with $2 \mathrm{nM}$ triiodothyronine and $20 \mathrm{nM}$ insulin (GIBCO BRL) for at least $3 \mathrm{~d}$; ucp1 expression was induced by adding $1 \mu \mathrm{M}$ retinoic acid or isoproterenol for $6 \mathrm{~h}$.

Immunohistochemical and cytochemical analyses. Immunodetection of SV40 TAg was performed using a monoclonal anti-SV40 TAg antibody (Ab-2; Calbiochem, La Jolla, CA). Cells were fixed with $100 \%$ ethanol, rinsed with PBS, and incubated with a 1:100 dilution of the primary antibody for $45 \mathrm{~min}$ at $37^{\circ} \mathrm{C}$. After washing, samples were incubated with biotinylated horse anti-mouse IgG and streptavidinfluorescein isothiocyanate (1:100). To confirm the TAg nuclear labeling, cells were treated for 5 min with propidium iodide. Cellular lipid accumulation was detected on the basis of red oil coloration (13).

Binding assays. Cells were grown $24 \mathrm{~h}$ before harvesting in the presence of $10 \%$ charcoal stripped FCS. After being rinsed twice with cold PBS, pelleted cells were frozen in liquid nitrogen. One volume of cells was homogenized in one volume of TEGW buffer $(20 \mathrm{mM}$ Tris$\mathrm{HCl}, 1 \mathrm{mM}$ EDTA, $20 \mathrm{mM}$ sodium tungstate $10 \%$ [vol/vol] glycerol, $\mathrm{pH} 7.4$, at $20^{\circ} \mathrm{C}$ ) in a Teflon-glass Potter-Elvehjem (Poly Labo, Strasbourg, France) apparatus. Cytosols obtained after centrifugation at $4^{\circ} \mathrm{C}$ at $15,000 \mathrm{~g}$ for $15 \mathrm{~min}$ were incubated for $4 \mathrm{~h}$ at $4^{\circ} \mathrm{C}$ with $10 \mathrm{nM}$ $\left[{ }^{3} \mathrm{H}\right]$ aldosterone (Amersham) in the absence or presence of a 100 -fold excess unlabeled aldosterone or RU38486 (a generous gift of RousselUclaf, Romainville, France). Bound and unbound steroids were separated by the dextran-charcoal technique. Values of binding parameters were determined at equilibrium by Scatchard analysis using a computerized method as described previously (6).

Table I. Characteristics of P1-TAg Transgenic Mice

\begin{tabular}{|c|c|c|c|c|}
\hline Founder & Sex & $\begin{array}{l}\text { Age of } \\
\text { death }\end{array}$ & $\begin{array}{c}\text { Copy } \\
\text { number }\end{array}$ & Localization of liposarcomas \\
\hline
\end{tabular}

$\begin{array}{lcrrl}16 & \text { F } & 17 & 15 & \text { Interscapular and mediastinal } \\ 17 & \text { M } & 5 & 5 & \text { Perirachidian } \\ 20 & \text { F } & 15 & 2 & \text { Interscapular and mediastinal } \\ 34 & \text { F } & 2 & 10 & \text { Dorsal subcutaneous } \\ 37 & \text { F } & 2 & 1 & \text { Dorsal subcutaneous }\end{array}$

Number of integrated transgene copies was determined by Southern blot analysis after digestion of $10 \mu \mathrm{g}$ genomic DNA with SalI and hybridization with the HA-TAg transgene following standard techniques. 

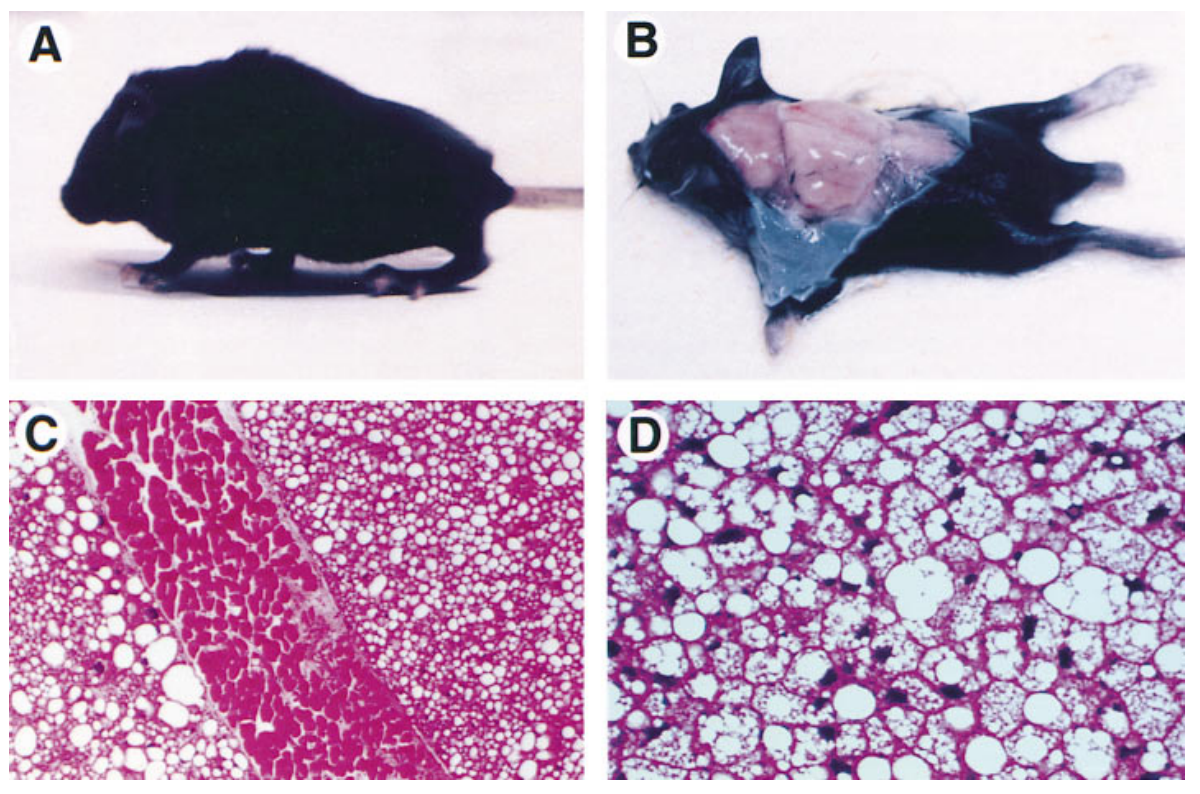

Figure 2. Liposarcoma development in P1-TAg transgenic mice. $(A)$ Founder 37 presented with a voluminous dorsal mass. (B) Postmortem macroscopic examination revealed the presence of two $3 \times 2 \mathrm{~cm}$ large tumors (inferior and superior) in the interscapular region of founder 37, which were removed and used to derive the T37i and T37s cell lines, respectively. ( $C$ and $D$ ) Hematoxylin and eosin-stained sections of a paravertebral liposarcoma from founder 37 , infiltrating striated muscle tissue $(C$, $\times 250$ ). Note the multivacuolated cells with lipid droplets and atypical nuclei $(D$, $\times 400$ ).

Triglyceride measurements. Undifferentiated T37i cells were plated in 12-well plates at a density of $5 \times 10^{4}$ cells per well and grown for $7 \mathrm{~d}$ in the presence of $10^{-8} \mathrm{M}$ aldosterone or $2 \mathrm{nM}$ triiodothyronine and $20 \mathrm{nM}$ insulin. Cells were rinsed twice with cold PBS, harvested in 250 $\mu 1$ PBS with a rubber policeman, and counted. Cells were subsequently disrupted by sonication $(10 \mathrm{~s} \times 2)$ and homogenates centrifuged for $10 \mathrm{~min}$ at $12,000 \mathrm{rpm}$ at $4^{\circ} \mathrm{C}$. The protein concentration was measured in the supernatant by the Bradford technique; triglyceride content was determined using a colorimetric determination kit (procedure 336; Sigma Chemical Co., St. Louis, MO).

\section{Results}

We have generated transgenic mice carrying the SV40 TAg under the control of the hMR proximal P1 promoter. Five transgenic founders were obtained, which all died within a few weeks after birth (Table I). Only female mouse 20 produced offspring, although none of the six pups inherited the transgene, preventing establishment of a lineage. Macroscopic examination of transgenic animals revealed the presence of large dorsal subcutaneous tumors, resulting in a characteristic buffalo appearance (Fig. 2, $A$ and $B$ ). In some transgenic mice, other neoplastic localizations were detected in the mediastinum and paravertebral region. All tumors were histologically identified as malignant liposarcomas displaying a lobular pattern and some of them were infiltrating striated muscle tissue (Fig. 2 C). The cells showed varying degrees of differentiation, but most were granular and multivacuolated with lipid droplets and major nuclear abnormalities (Fig. 2D). Systematic histopathological examination disclosed liposarcomatous foci in the pleura, the pericardium, and in the perirenal region. No other tumors were observed in other organs of these animals (kidney, lung, brain, heart, liver, muscle, spleen, colon, salivary glands, skin); however, some cardiomyocytes exhibited nuclear abnormalities (data not shown).

SV40 TAg mRNA expression was analyzed in various tissues of founders 34 and 37 by ribonuclease protection assay.
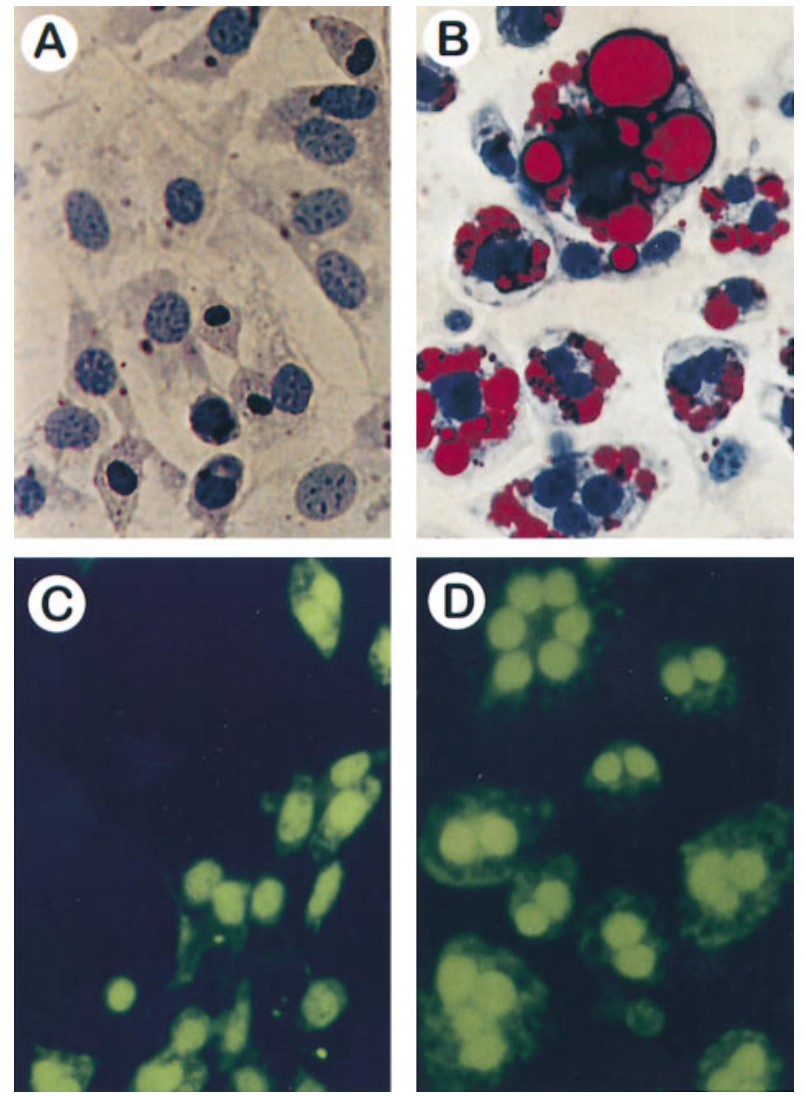

Figure 4. Establishment of a new brown adipocyte cell line. The T37i cell line was derived from the dorsal inferior liposarcoma from founder 37. Treatment of undifferentiated cells $(A)$ with insulin and triiodothyronine induced differentiation into brown adipocytes with multivacuolar lipid accumulation, as evidenced by red oil staining $(B)$. Characteristic nuclear staining with a monoclonal anti-TAg antibody was seen in both undifferentiated $(C)$ and differentiated $(D)$ T37i cells. $\times 800$. 
A.

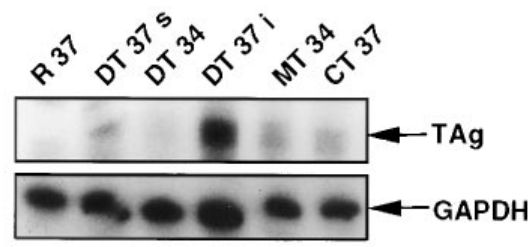

B.

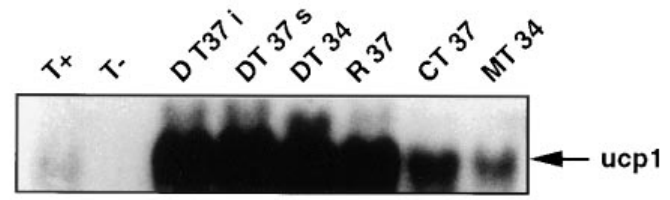

c.

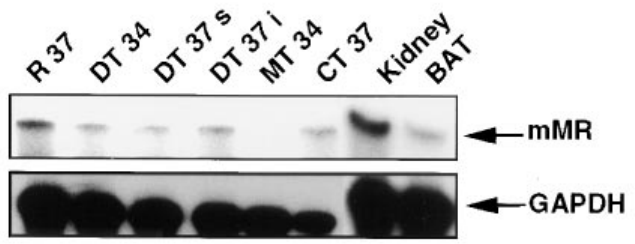

Figure 3. Expression of SV40 TAg, ucp1, and mMR mRNA in various hibernomas of founders 34 and 37. $(A$ and $C$ ) Ribonuclease protection assay was used to detect $\operatorname{TAg}(A)$ and $\mathrm{mMR}(C)$ expression in RNAs originating from a paravertebral, a dorsal superior, a dorsal inferior, and a cervical tumor of mouse 37 ( $R 37, D T 37 s, D T 37 i$, and $C T 37$, respectively), as well as from a dorsal and a mediastinal tumor of mouse 34 (DT 34 and MT 34). Endogenous mMR mRNA was detected in normal BAT. Total mouse kidney RNA was used as a positive control for MR expression, whereas a rat GAPDH probe was used as internal control in ribonuclease protection assays. $(B)$ ucp1 expression in neoplastic tissues was detected by Northern blot analysis. $T+$, differentiated $1 \mathrm{~B} 8$ cells treated with $1 \mu \mathrm{M}$ norepinephrine, positive control for ucp1 expression; $T$-, differentiated 1B8 cells, nontreated, negative control. The presence of two 1.6- or 1.9-kb ucp1 transcripts corresponds to different polyadenylation sites.

All liposarcomas were shown to express significant amounts of TAg, with highest levels in the inferior dorsal tumor of founder 37 (Fig. $3 \mathrm{~A}$ ); TAg expression was largely independent of the integrated transgene copy number (see Table I). The interscapular localization of liposarcomas together with their histomorphology were highly suggestive of malignant BAT tumors (hibernomas). This origin was confirmed by demonstrating expression of the mitochondrial uncoupling protein ucp1, a BAT-specific gene product, in liposarcomas of mice 34 and 37 (Fig. 3 B).

The occurrence of hibernomas in all transgenic mice carrying the SV40 TAg under the control of the hMR P1 proximal promoter was totally unexpected and prompted us to investigate whether BAT could be a site of MR gene expression. Ribonuclease protection assays were performed on total RNA from tumors as well as from BAT of nontransgenic animals. Endogenous mMR transcripts were detected in both normal and neoplastic BAT, providing conclusive evidence for MR gene transcription in BAT, although to a lesser extent than in the kidney (Fig. $3 C$ ). These results further indicate that SV40 TAg expression and hibernoma formation in transgenic mice are the consequence of appropriate tissue-specific expression of the transgene.
Given our interest in establishing a mineralocorticoid-sensitive cellular model, we derived three cell lines from hibernomas of mice 34 and 37; one of them, cell line T37i, originating from the inferior dorsal tumor of transgenic mouse 37, was further characterized. This cell line was subcultured for more than 10 passages over 3 mo, and subcloned by limiting dilution. Under normal culture conditions, T37i cells displayed a fibroblast-like appearance (Fig. $4 A$ ). After reaching confluency and additional treatment for 3-5 d with $20 \mathrm{nM}$ insulin and $2 \mathrm{nM}$ triiodothyronine, two known positive regulators of adipogenic differentiation, a striking morphological modification was observed with cells becoming larger and the appearance of numerous intracytoplasmic vacuoles consisting of small lipid droplets, demonstrated by red staining with oil red O (Fig. 4B). The majority of the cells presented with multiple nuclei and underwent terminal adipocyte differentiation in a reproducible manner. It should be noted that the two other cell lines T37s and T34, derived from a superior dorsal tumor of transgenic mouse 37 and a dorsal hibernoma of mouse 34, respectively, did not fully differentiate, even though cultured under the same conditions. Immunofluorescence studies showed that both undifferentiated and differentiated T37i cells expressed TAg, as demonstrated by specific nuclear labeling (Fig. 4, C and $D$ ).

ucp1 expression was also studied in T37i cells to establish whether these cells maintained differentiated features of BAT. Whereas undifferentiated T37i cells did not express the ucp1 gene even upon stimulation, isoproterenol $(1 \mu \mathrm{M})$ and retinoic acid $(1 \mu \mathrm{M})$ significantly activated ucp 1 gene expression in terminally differentiated cells (Fig. $5 A$ ). These results indicate that the tumor-derived T37i clone behaves as a preadipocyte

\section{T37i cells}

\section{Undifferentiated Differentiated}

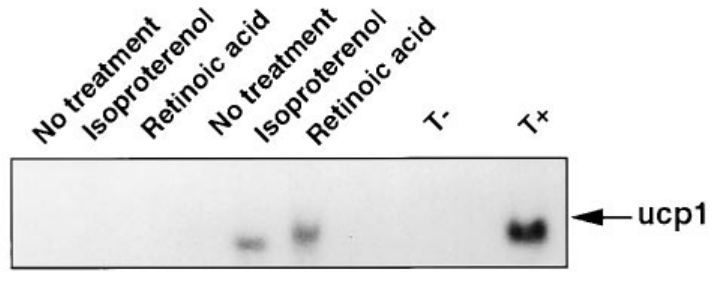

T37i

B.

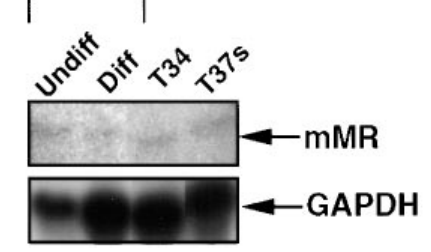

Figure 5. Expression of ucp1 and mMR in T37i cells. (A) ucp1 transcripts were detected by Northern blot analysis only in differentiated T37i cells treated with $1 \mu \mathrm{M}$ isoproterenol or retinoic acid. No ucp1 mRNA is detected in either undifferentiated or untreated differentiated cells. $(B)$ Both undifferentiated and differentiated T37i cells express mMR mRNA, as detected by ribonuclease protection assay. mMR transcripts are also detected in the cell line T34 derived from a dorsal hibernoma of founder 34 , as well as in cell line T37s, derived from the superior dorsal tumor of founder 37. 


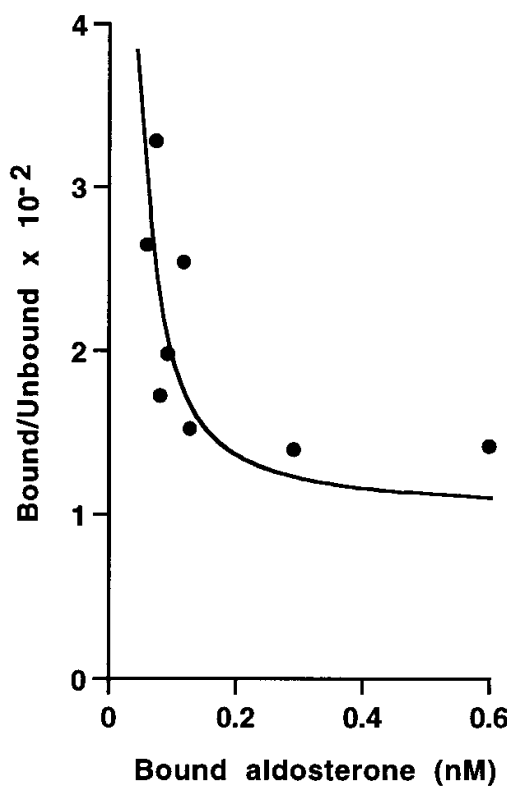

specific binding sites $(n=56 \pm 7 \mathrm{pM}), K_{\mathrm{d}}$ is the dissociation constant $\left(K_{\mathrm{d}}=0.81 \pm 0.49 \mathrm{nM}\right)$, and $\beta$ is the constant of nonspecific binding $(\beta=0.01)$. Mean values are given with the corresponding intraexperimental SD. Experimental points are means of triplicate determinations.

progenitor cell, which could be fully differentiated into a brown adipocyte phenotype under appropriate conditions.

To investigate whether MR expression was maintained in T37i cells, the presence of mMR at the mRNA and protein level was sought. Both undifferentiated and differentiated T37i cells expressed low but detectable amounts of mMR transcripts, as evidenced by ribonuclease protection assay (Fig. 5 $B$ ); note that the two other cell lines T37s and T34 also contained significant levels of mMR mRNA. Finally, specific aldosterone binding sites were detected in the cytosolic fractions of undifferentiated T37i cells $(34 \pm 4 \mathrm{fmol} / \mathrm{mg}$ protein, $n=3)$; nonspecific binding was $<45 \%$. These sites were identified as MRs since aldosterone binding was totally unaffected by the addition of a 100-fold excess of RU38486, a glucocorticoid receptor (GR) ligand (data not shown). Scatchard plot representation of aldosterone binding in the cytosol of T37i cells is presented in Fig. 6. Computerized analysis of the experimental data revealed the presence of one class of high-affinity binding sites with a $K_{\mathrm{d}}$ value estimated at $0.81 \pm 0.49 \mathrm{nM}$ and a maximum number of sites $n=56 \pm 7 \mathrm{pM}$ (corresponding to $16 \pm 2$ $\mathrm{fmol} / \mathrm{mg}$ protein). In contrast, MR concentration was much lower in differentiated cells ( $8 \mathrm{fmol} / \mathrm{mg}$ protein), suggesting that in this cell line MR expression might be repressed during the differentiation process.

In an attempt to assess a biological role for mineralocorticoids in BAT, we have studied the influence of aldosterone treatment on T37i cell differentiation. A significant, twofold increase in triglyceride accumulation of T37i cells was observed after a 7-d treatment with $10^{-8} \mathrm{nM}$ aldosterone, as compared with nontreated cells $(118.9 \pm 19.2$ vs. $56.4 \pm 5.8 \mathrm{mg}$ triglycerides/g of protein, $n=3, P<0.01$ ), corresponding to $\sim 50 \%$ of triglyceride content observed after insulin-thyroid hormone treatment $(215.2 \pm 23.9 \mathrm{mg}$ triglycerides $/ \mathrm{g}$ of protein $)$. These results were highly suggestive of an involvement of aldosterone in promoting brown adipocyte differentiation.

\section{Discussion}

We have shown recently that expression of multiple hMR mRNA isoforms is under the control of alternative promoters, which are submitted to differential hormonal control (10). To identify particular cis-acting elements involved in tissue-specific and developmental hMR expression, we have developed transgenic animal models, in which the SV40 TAg was placed under the control of the hMR P1 or P2 promoter regions. Targeted oncogenesis was chosen for the additional possibility of establishing immortalized cell lines, originating from various aldosterone target tissues, which could be used to further define cellular and molecular events underlying MR-mediated effects. During the course of these studies, unexpected findings were obtained with the transgenic mice harboring the P1-TAg hybrid gene. Whereas no tumors were apparent in classical aldosterone target tissues such as kidney or colon, all transgenic founders prematurely died from hibernomas. Subsequently, we demonstrated that MR is normally expressed in BAT. The hMR P1 promoter sequences from -965 to +216 thus clearly contain elements sufficient to direct tissue-specific expression of the transgene in BAT. Early development of hibernomas in $\mathrm{P} 1-\mathrm{TAg}$ mice indicates that the $\mathrm{P} 1$ region is transcriptionally active during early life, in agreement with recent studies reporting MR expression in the mouse fetus from E13.5 onwards (14). The fact that no other tumors were found in these animals, despite expression of TAg in several other tissues, including kidney, heart, and brain (Le Menuet, D., M.-C. Zennaro, S. Viengchareun, and M. Lombès, unpublished results), supports previous observations that BAT possesses a high tumor potential $(15,16)$.

This work, which demonstrates that BAT is a novel mineralocorticoid target tissue, constitutes the first step of a detailed in vivo study of regulatory elements of the hMR gene. TAg expression in BAT of $\mathrm{P} 1-\mathrm{TAg}$ mice is promoter specific, since transgenic animals in which TAg was driven by the distal hMR promoter P2 do not develop hibernomas at $36 \mathrm{wk}$. To identify functional elements responsible for tissue-specific expression in BAT, the hMR P1 region was aligned with promoter sequences of the BAT specific gene ucp1. A strong enhancer located at $-2.4 \mathrm{~kb}$ in the 5 -flanking region of the rat ucp 1 gene has been shown recently to be essential for brown fat specificity as well as hormonal regulation $(17,18)$. Interestingly, some P1 promoter sequences showed high degrees of nucleotide identity with specific motifs located in the ucp1 enhancer, in particular the Ets1/NF1 binding sites, the TRE, RXR/TR regions, and the ucp gene-activating region UAR (18). Thus, these sequences might represent important cis-acting elements involved in tissue-specific expression of hMR. However, further studies are required to precisely determine the role played by these elements in directing mMR expression in BAT.

We then derived a new cell line, T37i, from a dorsal hibernoma of one transgenic founder. T37i cells exhibited differentiated features of BAT under appropriate conditions, as demonstrated by expression of ucp1 after adrenergic or retinoic acid stimulation. MR expression is maintained in these cells, constituting a unique model to unravel molecular mechanisms of aldosterone action. Indeed, despite many attempts to estab- 
lish a mammalian mineralocorticoid-sensitive cell line (19-21), up until now no cellular model has been described which maintains adequate response to aldosterone in terms of ion transport or transactivation of a reporter gene. Besides its potential usefulness to study in detail expression and regulation of specific BAT genes, the T37i cell line appears to represent an attractive experimental system suitable to examine regulated MR expression and to identify new aldosterone target genes. Furthermore, this and other potential cellular models derived from our transgenic animals, in which the $\mathrm{P} 1$ or $\mathrm{P} 2$ promoters are stably integrated into the genome, will allow functional analysis of hMR regulatory elements in an appropriate chromatin structure.

Recent studies have clearly demonstrated that aldosterone action is not only confined to the control of sodium and potassium homeostasis in tight epithelia but rather appears to be pleiotropic, including specific mineralocorticoid effects in the central nervous and cardiovascular systems $(22,23)$. Recently, a distinction between epithelial and nonepithelial target tissues in terms of aldosterone action has been proposed. Indeed, mineralocorticoid specificity is closely related to the presence of the enzyme 11 $\beta$-hydroxysteroid dehydrogenase 2 (11HSD2), which is present in sodium transporting epithelia; in unprotected tissues, MR appears to be predominantly occupied by glucocorticoids, which are not converted to inactive 11-dehydro-congeners, although specific aldosterone actions have also been described (23-25). BAT seems to be a bona fide nonepithelial target tissue, since we failed to detect 11HSD2 mRNA either in hibernomas or in the T37i cell line (data not shown).

The specific role of aldosterone in BAT remains to be elucidated. Our preliminary studies demonstrate that aldosterone is able to induce differentiation of T37i cells into brown adipocytes. This is in accord with recent data showing that aldosterone promotes differentiation of 3T3-L1 cells into adipocytes (26). In this context, an enlargement of brown fat depots in the perirenal and periadrenal regions has been reported recently in patients affected by primary hyperaldosteronism (27). Involvement of aldosterone and MR in the regulation of nonshivering thermogenesis should also be considered. Indeed, effects of glucocorticoids in BAT are well documented $(28,29)$. In vivo, corticosterone has been shown to decrease thermogenic activity, to increase lipid accumulation, and to be a potent inhibitor of ucp1 gene expression; further investigation should clarify whether these effects are mediated via GR and/ or MR. Finally, recent data have demonstrated heterodimerization between MR and GR on different promoters (10, 30, 31). Colocalization of both receptors in several unprotected tissues suggests a role for MR as a widespread dimerization partner for GR in mediating glucocorticoid effects.

In conclusion, targeted oncogenesis appeared to be a powerful strategy for discovering new aldosterone-responsive tissues and for deriving differentiated cell lines constituting valuable models for the evaluation of MR function in vivo. Future studies of P1-TAg and P2-TAg transgenic animals should thus allow precise characterization of alternative promoter usage in directing tissue-specific and developmental MR gene expression.

\section{Acknowledgments}

We thank Dr. L.-M. Houdebine for providing us with the transgenic vector H31 and Dr. I. Cerutti and the "Service d'Expérimentation
Animale et de Transgenèse" for the generation of transgenic animals. The generous supplies of the mMR probe from Drs. G. Schütz and S. Berger and of the mouse 11ßHSD2 cDNA from Dr. Tim Cole (Baker Institute, Prahran, Australia) are gratefully appreciated. We also wish to thank Drs. N. Farman and J.-P. Bonvalet for helpful discussion, and G. Delrue for illustrations.

M.-C. Zennaro is supported by a fellowship from the Fondation pour la Recherche Médicale.

\section{References}

1. Funder, J.W. 1993. Aldosterone action. Annu. Rev. Physiol. 55:115-130.

2. Anderson, N.S., and D.D. Fanestil. 1976. Corticoid receptors in rat brain: evidence for an aldosterone receptor. Endocrinology. 98:676-684.

3. Reul, J.M.H.M., and E.R. de Kloet. 1985. Two receptor systems for corticosterone in rat brain: microdistribution and differential occupation. Endocrinology. 117:2505-2512.

4. Pearce, P., and J.W. Funder. 1987. High affinity aldosterone binding sites (type I receptors) in rat heart. J. Clin. Exp. Pharmacol. Physiol. 14:859-866.

5. Lombès, M., N. Alfaidy, E. Eugene, A. Lessana, N. Farman, and J.-P. Bonvalet. 1995. Prerequisite for cardiac aldosterone action: mineralocorticoid receptor and $11 \beta$-hydroxysteroid dehydrogenase in the human heart. Circulation. 92:175-182.

6. Lombès, M., M.-E. Oblin, J.M. Gasc, E.E. Baulieu, N. Farman, and J.-P. Bonvalet. 1992. Immunohistochemical and biochemical evidence for a cardiovascular mineralocorticoid receptor. Circ. Res. 71:503-510.

7. Zennaro, M.C., M.C. Keightley, Y. Kotelevtsev, G. Conway, F. Soubrier, and P.J. Fuller. 1995. Human mineralocorticoid receptor genomic structure and identification of expressed isoforms. J. Biol. Chem. 270:21016-21020.

8. Kwak, S.P., P.D. Patel, R.C. Thompson, H. Akil, and S.J. Watson. 1993. 5 '-heterogeneity of the mineralocorticoid receptor messenger ribonucleic acid: differential expression and regulation of splice variants within the rat hippocampus. Endocrinology. 133:2344-2350.

9. Zennaro, M.-C., N. Farman, J.-P. Bonvalet, and M. Lombès. 1997. Tissue-specific expression of $\alpha$ and $\beta$ mRNA isoforms of the human mineralocorticoid receptor in normal and pathological states. J. Clin. Endocrinol. Metab. 82: 1345-1352.

10. Zennaro, M.-C., D. Le Menuet, and M. Lombès. 1996. Characterization of the human mineralocorticoid receptor gene 5 '-regulatory region: evidence for differential hormonal regulation of two alternative promoters via non-classical mechanisms. Mol. Endocrinol. 10:1549-1560.

11. Escoubet, B., C. Coureau, M. Blot-Chabaud, J.P. Bonvalet, and N. Farman. 1996. Corticosteroid receptor mRNA expression is unaffected by corticosteroids in the rat kidney, heart and colon. Am. J. Physiol. 270:C1343-C1353.

12. Sambrook, J., E.F. Fritsch, and T. Maniatis. 1989. Molecular Cloning: A Laboratory Manual. 2nd ed. Cold Spring Harbor, NY.

13. Green, H., and O. Kehinde. 1974. Sublines of mouse 3 T3 cells that accumulate lipids. Cell. 1:113-116.

14. Brown, R.W., R. Diaz, A.C. Robson, Y.V. Kotelevtsev, J.J. Mullins, M.H. Kaufman, and J.R. Seckl. 1996. The ontogeny of 11ß-hydroxysteroid dehydrogenase type 2 and mineralocorticoid receptor gene expression reveal intricate control of glucocorticoid action in development. Endocrinology. 137: 794-797.

15. Fox, N., R. Crooke, L.-H.S. Hwang, U. Schibler, B. Knowles, and D. Solter. 1989. Metastatic hibernomas in transgenic mice expressing an $\alpha$-amylase-SV40 T antigen hybrid gene. Science. 244:460-463.

16. Ross, S.R., L. Choy, R.A. Graves, N. Fox, V. Solevjeva, S. Klaus, D. Ricquier, and B.M. Spiegelman. 1992. Hibernoma formation in transgenic mice and isolation of a brown adipocyte cell line expressing the uncoupling protein gene. Proc. Natl. Acad. Sci. USA. 89:7561-7565.

17. Kozak, U.C., J. Kopecky, J. Teisinger, S. Enerback, B. Boyer, and L.P. Kozak. 1994. An upstream enhancer regulating brown fat specific expression of the mitochondrial uncoupling protein gene. Mol. Cell Biol. 14:59-67.

18. Larose, M., A.-M. Cassard-Doulcier, C. Fleury, F. Serra, O. Champigny, F. Bouillard, and D. Ricquier. 1996. Essential cis-acting elements in rat uncoupling protein gene are in an enhancer containing a complex retinoic acid response domain. J. Biol. Chem. 271:31533-31542.

19. Stoos, B.A., A. Naray-Fejes-Toth, O.A. Carretero, S. Ito, and G. FejesToth. 1991. Characterization of a mouse cortical collecting duct cell line. Kidney Int. 39:1168-1175.

20. Priè, D., G. Friedlander, C. Coureau, A. Vandevalle, R. Cassingena, and P.M. Ronco. 1995. Role of adenosine on glucagon-induced cAMP in human collecting duct cell line. Kidney Int. 47:1310-1318.

21. Blot-Chabaud, M., M. Laplace, F. Cluzeaud, C. Capurro, R. Cassingena, A. Vandevalle, N. Farman, and J.-P. Bonvalet. 1996. Characteristics of a rat cortical collecting duct cell line that maintains high transepithelial resistance. Kidney Int. 50:367-376.

22. Joels, M., and E.R. de Kloet. 1995. Corticosteroid hormones: endocrine messengers in the brain. N. Physiol. Sci. 10:71-76. 
23. Young, M., M. Fullerton, R. Dilley, and J.W. Funder. 1994. Mineralocorticoids, hypertension and cardiac fibrosis. J. Clin. Invest. 93:2578-2583.

24. Brilla, C.G., R. Pick, L.B. Tan, J.S. Janicli, and K.T. Weber. 1990. Remodeling of the rat right and left ventricle in experimental hypertension. Circ. Res. 67:1355-1364.

25. Gomez-Sanchez, E.P., M.T. Venkataraman, and D. Thwaites. 1990. ICV infusion of corticosterone antagonizes ICV-aldosterone hypertension. Am. J. Physiol. 258:E649-E653.

26. Rondinone, C.M., D. Robbard, and M.E. Baker. 1993. Aldosterone stimulates differentiation of mouse 3T3-L1 cells into adipocytes. Endocrinology. 132:2421-2426.

27. Garruti, G., and D. Ricquier. 1992. Analysis of uncoupling protein and its mRNA in adipose tissue of adipose deposits of adult humans. Int. J. Obesity.
$16: 383-390$

28. Moriscot, A., R. Rabelo, and A.C. Bianco. 1993. Corticosterone inhibits uncoupling protein gene expression in brown adipose tissue. Am. J. Physiol. 265:E81-E87.

29. Strack, A.M., M.J. Bradbury, and M.F. Dallman. 1995. Corticosterone decreases nonshivering thermogenesis and increases lipid storage in brown adipose tissue. Am. J. Physiol. 268:R183-R191.

30. Trapp, T., R. Rupprecht, M. Castrèn, J.M.H.M. Reul, and F. Holsboer 1994. Heterodimerization between mineralocorticoid and glucocorticoid receptor: a new principle of glucocorticoid action in the CNS. Neuron. 13:1457-1462.

31. Liu, W., J. Wang, N.K. Sauter, and D. Pearce. 1995. Steroid receptor heterodimerization demonstrated in vitro and in vivo. Proc. Natl. Acad. Sci. USA. 92:12480-12484. 